\title{
Septic shock and the use of norepinephrine in a high dependency unit - mortality and adverse events
}

\author{
M Hallengren ${ }^{1 *}, \mathrm{P}$ Åstrand ${ }^{2}, \mathrm{~S}$ Eksborg $^{3}, \mathrm{H} \mathrm{Barle}^{4}, \mathrm{C} \mathrm{Frostell}^{4}$ \\ From ESICM LIVES 2015 \\ Berlin, Germany. 3-7 October 2015
}

\section{Introduction}

Septic shock is associated with high mortality. Elderly and multimorbid patients are not always eligible for intensive care unit (ICU) admission. Intravenous (IV) infusion of norepinephrine (NE) is an accepted treatment for hypotension in septic shock. Use of a vasopressor outside the ICU is poorly evaluated.

\section{Objectives}

To describe the severity of disease using Acute Physiology and Chronic Health Evaluation (APACHE-II) scoring, mortality and adverse events (AE); in patients with septic shock receiving IV fluid and NE in a high dependency unit (HDU) at the Dept of Medicine.

\section{Methods}

A retrospective review of 91 patients with sepsis treated with antibiotics, IV fluids and NE for hypotension. Data on HDU- and 30-day mortality, standardized mortality ratio (SMR) as well as adverse events (necrosis and arrhythmia) were collected. The route of administration of fluids and NE, via peripheral venous catheter (PVC) or central venous catheter (CVC), was registered. All patients were monitored with pulse oximetry, a 3-point ECG and had blood pressure measured non-invasively. Nurse:patient ratio was $\geq 1: 3$ in the HDU.

\section{Results}

Median age (min-max) was 81 (43-96) years and median APACHE-II was 26 (12-42) points. Patients not reaching a mean arterial pressure (MAP) $>65 \mathrm{~mm} \mathrm{Hg}$ within 12 hours had poor outcome, see Figure 1. HDU-mortality

${ }^{1}$ Karolinska Institutet, Clinical Sciences Danderyd Hospital, Stockholm, Sweden

Full list of author information is available at the end of the article

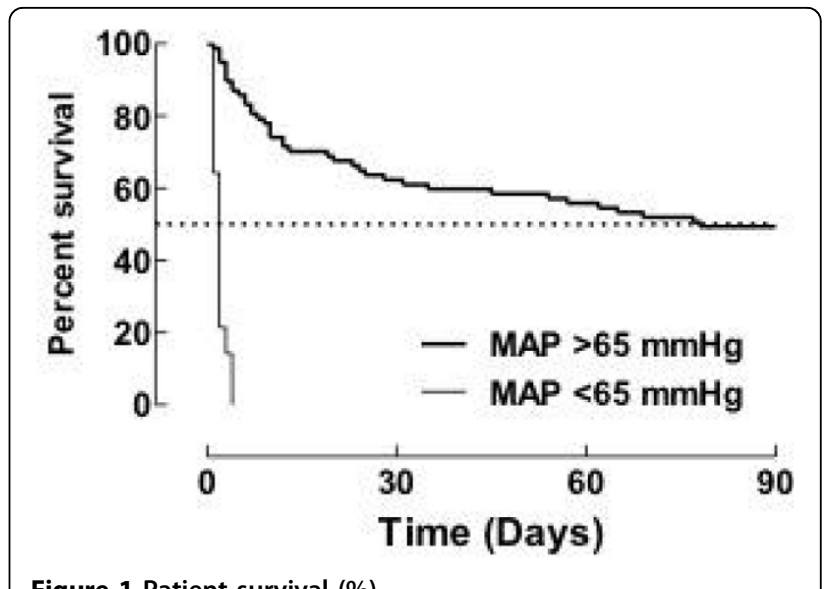

Figure 1 Patient survival (\%)

was $27 \%(\mathrm{n}=25)$, with SMR as $0.443(95 \% \mathrm{CI}: 0.287$ $0.654)$; and 30-day mortality was $47 \%(\mathrm{n}=43)$. NE (maximum 0.2 microgram $/ \mathrm{kg} / \mathrm{min}$ ) was administered via PVC in $87 \%(\mathrm{n}=79)$ and via CVC in $13 \%(\mathrm{n}=12)$ of patients, duration up to 72 hours. No skin necrosis was noted; one patient developed sinus tachycardia and died shortly after having the NE-infusion stopped.

\section{Conclusions}

Patients treated with NE for hypotension in septic shock had a better HDU survival than expected. This study does not indicate frequent $\mathrm{AEs}$ when administering $\mathrm{NE}$ via a PVC.

\section{Authors' details}

'Karolinska Institutet, Clinical Sciences Danderyd Hospital, Stockholm, Sweden. ${ }^{2}$ Karolinska Institutet, Department of Internal Medicine Danderyd Hospital, Stockholm, Sweden. ${ }^{3}$ Karolinska Institutet, Stockholm, Sweden.

\section{SpringerOpen ${ }^{\circ}$}

(c) 2015 Hallengren et al.; This is an Open Access article distributed under the terms of the Creative Commons Attribution License (http://creativecommons.org/licenses/by/4.0), which permits unrestricted use, distribution, and reproduction in any medium, provided the original work is properly cited. 
${ }^{4}$ Karolinska Institutet, Department of Anaesthesia and Intensive Care, Danderyd Hospital, Stockholm, Sweden.

Published: 1 October 2015

doi:10.1186/2197-425X-3-S1-A877

Cite this article as: Hallengren et al: Septic shock and the use of norepinephrine in a high dependency unit - mortality and adverse events. Intensive Care Medicine Experimental 2015 3(Suppl 1):A877.

\section{Submit your manuscript to a SpringerOpen ${ }^{\mathcal{O}}$ journal and benefit from:}

- Convenient online submission

- Rigorous peer review

- Immediate publication on acceptance

- Open access: articles freely available online

- High visibility within the field

- Retaining the copyright to your article

Submit your next manuscript at $\gg$ springeropen.com 